\title{
Nanostructural zinc oxide hollow spheres: A facile synthesis and catalytic properties
}

\author{
Siddaramanna Ashoka ${ }^{a}$, Pallellappa Chithaiah ${ }^{a}$, Kumarappa Veerappa Thipperudraiah ${ }^{\text {b }}$ \\ Gujjarahalli Thimmanna Chandrappa ${ }^{\mathrm{a}, *}$

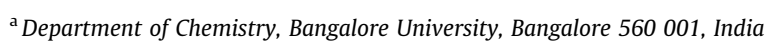 \\ ${ }^{\mathrm{b}}$ Department of Physics, Ambedkar First Grade College, Bangalore 560 008, India
}

\section{A R T I C L E I N F O}

\section{Article history:}

Received 1 January 2010

Received in revised form 25 June 2010

Accepted 28 June 2010

Available online 31 July 2010

\section{Keywords:}

Chemical synthesis

Ethylene glycol

ZnO

Hollow spheres

Catalysis

\begin{abstract}
A B S T R A C T
The development of reproducible procedures for the synthesis and organization of nanostructured metal oxides is important in order to exploit the unique properties of these materials for practical applications. The present work describes the transformation of $\left.\mathrm{Zn}\left(\mathrm{NH}_{3}\right)_{4}\right]^{2+}$ into hollow structured $\mathrm{ZnO}$ materials through solvothermal decomposition. An increase in ammonia concentration in the reaction medium, significantly changes the morphology of $\mathrm{ZnO}$ from spheres made of nanoparticles $(20-30 \mathrm{~nm})$ to hollow spheres composed of nanorods $(200-350 \mathrm{~nm})$ or to free microrods as evidenced from scanning and transmission electron micrographs (SEM/TEM). The powder X-ray diffraction (XRD) pattern of ZnO confirms formation of the wurtzite structure. Raman and Energy-dispersive spectroscopic (EDS) studies indicate the presence of oxygen deficiency in $\mathrm{ZnO}$. The investigation on the catalytic behavior of $\mathrm{ZnO}$ in the synthesis of (4-methoxyphenyl)(phenyl) methanone (MPPM) by Friedel-Crafts acylation of anisole with benzoyl chloride has also been carried out. The results reveal that the prepared $\mathrm{ZnO}$ could produce $\sim 98 \%$ of yield compared to $41 \%$ produced by commercial $\mathrm{ZnO}$.
\end{abstract}

(C) 2010 Elsevier B.V. All rights reserved.

\section{Introduction}

$\mathrm{ZnO}$, a polar inorganic material has been known for its many interesting physical and chemical properties, and for its potential applications in different areas including solar cells, sensors, varistors, UV lasers, surface acoustic wave devices, catalysis, and adsorption [1-7]. As a consequence, $\mathrm{ZnO}$ nanostructures with different morphologies, such as nanobelts, nanocombs, nanohelix, nanocables, hollow urchins, nanoplatelets, nanorings, nanosprings, and hierarchical nanostructures have been successfully fabricated with the aim of expanding the scope of its applications [8]. There is however, another important class of zinc oxide materials with interesting functionalities which merits special attention hollow spheres. In recent times, attention has been focused on the synthesis of $\mathrm{ZnO}$ hollow spheres in view of their potential for applications in the delivery of drugs, catalysis, chemical storage, microcapsule reactors and photoelectric materials [9]. Several methods have been developed for the fabrication of sub-micrometer hollow spheres of $\mathrm{ZnO}$ materials. For instance, $\mathrm{ZnO}$ hollow structures can be prepared by oxidation of vapor-deposited zinc, laser-assisted growth on the surface of ethanol droplets as templates, chemical vapor deposition on carbon nanotubes and pyrolysis [10-14]. All these processes, in which the shape, size and quality of the pro-

\footnotetext{
* Corresponding author. Tel.: +91 8022961350.

E-mail address: gtchandrappa@yahoo.co.in (G.T. Chandrappa).
}

duced shells remain more or less accidental, require high energies or complex set-ups. The self-assembly of $\mathrm{ZnO}$ nanoparticles into hollow structures is also made by solvothermal method [15] using coordination polymer, $\left[\mathrm{Zn}\left(4,4^{1} \text {-bipy }\right)(\mathrm{NCS})_{2}\right]_{n}$. However, this method requires prior synthesis of coordination polymer by a separate process. Recently, ZnO hollow spheres prepared using the sacrificial template route [16-19] has been reported. This method appears to be complicated since, first, a coating of the preferred shell material is formed on a template of the desired shape, and subsequently the template is subjected to heat treatment or dissolves in a suitable solvent to make the template-free hollow ZnO material.

In wet chemical synthesis, water is generally employed as a reaction medium to facilitate the production of $\mathrm{ZnO}$ in various morphologies. In conventional hydrothermal synthesis, water can adversely affect synthesis of the desired compounds due to the sensitivity of some precursor to hydrolysis [20]. The solvothermal method therefore, attracts many researchers for the preparation of various nano/micro structural materials by virtue of its unique reaction environment [7]. Organic solvents used in the solvothermal process, can effectively prevent the agglomeration and control the morphology development of the crystals. Crystal growth is significantly modified by physico-chemical properties of the solvent such as polarity, viscosity, softness and dielectric constant [21].

In this paper, we report a facile synthesis of tunable $\mathrm{ZnO}$ hollow spheres with the assistance of ethylene glycol and ammonia under 
mild conditions. The catalytic activity of the resulting $\mathrm{ZnO}$ hollow spheres for Friedel-Crafts acylation of anisole with benzoyl chloride has also been carried out.

\section{Experimental}

\subsection{Materials}

Zinc acetate dihydrate $\left[\mathrm{Zn}\left(\mathrm{CH}_{3} \mathrm{COO}\right)_{2} \cdot 2 \mathrm{H}_{2} \mathrm{O}\right]$, ethylene glycol $\left(\mathrm{C}_{2} \mathrm{H}_{6} \mathrm{O}_{2}\right)$, ammonia solution $\left(\mathrm{NH}_{4} \mathrm{OH}, 35.5 \%\right)$ and zinc oxide ( $\mathrm{ZnO})$ were purchased from Merck Limited and used without further purification. Double distilled water was used throughout the experiments.

\subsection{Synthesis of $\mathrm{ZnO}$ materials}

As in a typical solvothermal synthesis, $0.5 \mathrm{~g}$ zinc acetate $(2.27 \mathrm{mmol})$ was dissolved in $13 \mathrm{ml}$ ethylene glycol. To this, ammonia solution $(0.5-2 \mathrm{ml})$ was added in drops resulting in the formation of $\left[\mathrm{Zn}\left(\mathrm{NH}_{3}\right)_{4}\right]^{2+}$ clear solution. The clear solution was stirred for $10 \mathrm{~min}$ on a magnetic stirrer and transferred into Teflon-lined stainless steel autoclaves with a capacity of $20 \mathrm{ml}$. Autoclaves were sealed and kept at $160^{\circ} \mathrm{C}$ for 1 day under autogenous pressure. The resulting yellowish white solid was retrieved by centrifugation. The solid product was washed with distilled water followed by ethanol and finally dried at $70^{\circ} \mathrm{C}$ for $2 \mathrm{~h}$ in an electric oven.

\subsection{Catalytic property}

Benzoyl chloride $(0.1 \mathrm{mmol})$ was added to a mixture of solvothermally derived $\mathrm{ZnO}$ and anisole $(0.1 \mathrm{mmol})$ taken in dichloro methane at room temperature and stirred for $20 \mathrm{~min}$ on a magnetic stirrer in order to complete the reaction. After separation of the catalyst by filtration, the dichloromethane containing the product was then washed with an aqueous solution of sodium bicarbonate and dried over anhydrous sodium sulfate. The product MPPM was obtained on evaporation of the solvent. ${ }^{1} \mathrm{H}$ NMR and LCMS spectral studies were carried out on the product for identification.

\section{Materials characterization}

Powder XRD data were recorded on Philips X'pert PRO X-ray diffractometer with graphite monochromatized $\mathrm{Cu} \mathrm{K} \alpha$ radiation ( $\lambda=1.541 \AA$ ). The X-ray photoelectron spectroscopy (XPS) of ZnO was examined using ultra-high vacuum set-up equipped with a high resolution Gammadata-Scienta SES 2002 analyzer. A monochromatic Al $\mathrm{K} \alpha \mathrm{X}$-ray source $(1486.3 \mathrm{eV}$; anode operating at $14.5 \mathrm{kV}$ and $50 \mathrm{~mA}$ ) was used as incident radiation and pass energy of $200 \mathrm{eV}$ was chosen. The morphology of the $\mathrm{ZnO}$ was examined by JEOL-JSM-6490 LV scanning electron microscope and CM12 Philips transmission electron microscope equipped with EDS (Kevex Sigma TM Quasar, USA). Raman spectrum was recorded at room temperature with a confocal laser micro-Raman spectrometer (LABRMHR).

\section{Results and discussion}

\subsection{Powder X-ray diffraction}

Fig. 1a and $\mathrm{b}$ shows the PXRD patterns of the $\mathrm{ZnO}$ hollow spheres and commercial $\mathrm{ZnO}$, respectively. All the diffraction peaks can be indexed as the hexagonal phase of pure wurtzite $\mathrm{ZnO}$ structure. The $\mathrm{ZnO}$ hollow spheres have much broader and less intense peaks compared to the commercial $\mathrm{ZnO}$ powder due to particle size

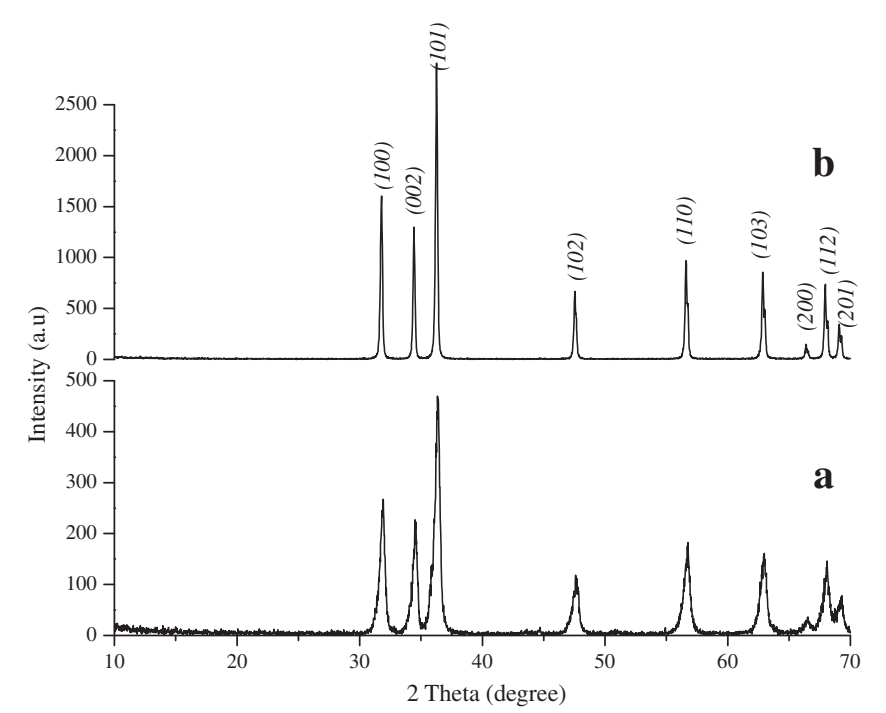

Fig. 1. PXRD pattern of the (a) hollow structured $\mathrm{ZnO}$ and (b) commercial $\mathrm{ZnO}$ powder.

broadening, which occurs when a sample is made up of very small crystallites [22].

\subsection{X-ray photoelectron spectroscopy}

The Zn 2p XPS spectra shown in Fig. 2a consist of $Z n 2 p_{1 / 2}$ and $2 p_{3 / 2}$ doublet peak. The $Z n 2 p_{3 / 2}$ line of the zinc oxides is generally observed at a lower binding energy of $1022.3 \mathrm{eV}$ and the $\mathrm{Zn} 2 \mathrm{p}_{1 / 2}$ peak at $1045.7 \mathrm{eV}$. The 01s spectrum (Fig. 2b) of the zinc oxide contains four peaks originating from oxide, hydroxides and adsorbed water. A low intense peak at $528.6 \mathrm{eV}$ along with a high intense peak at $530.4 \mathrm{eV}$ can be attributed to $\mathrm{O}^{2-}$ type of species associated with oxide of $\mathrm{Zn}$, which is in the form of $\mathrm{ZnO}$. The peaks at 531.8 and $533.2 \mathrm{eV}$ arise mainly from the hydroxide groups of $\mathrm{Zn}(\mathrm{OH})_{2}$ and adsorbed water, respectively. A comparison of the relative intensities of the four $\mathrm{O}(1 \mathrm{~s})$ peaks shows that the amount of oxide associated with $\mathrm{Zn}$ is more. Taking this fact into consideration along with the PXRD observation, the most probable species could be the $\mathrm{ZnO}[23]$.

\subsection{Mechanism and morphology of $\mathrm{ZnO}$}

Most of the transition metals form complexes with ammonia in aqueous solution [24]. The $\left[\mathrm{Zn}\left(\mathrm{NH}_{3}\right)_{4}\right]^{2+}$ complex is formed when ammonia solution is added to zinc acetate-ethylene glycol solution at room temperature (Eq. (1)). During solvothermal treatment, $\left[\mathrm{Zn}\left(\mathrm{NH}_{3}\right)_{4}\right]^{2+}$ complex undergoes dissociation to $\mathrm{ZnO}[25]$ as designated in Eq. (2)

$\mathrm{Zn}^{2+}+4 \mathrm{NH}_{3} \rightleftharpoons\left[\mathrm{Zn}\left(\mathrm{NH}_{3}\right)_{4}\right]^{2+}$
$\left[\mathrm{Zn}\left(\mathrm{NH}_{3}\right)_{4}\right]^{2+}+2 \mathrm{OH}^{-} \rightleftharpoons \mathrm{ZnO}+4 \mathrm{NH}_{3}+\mathrm{H}_{2} \mathrm{O}$

The growth of $\mathrm{ZnO}$ depends mainly on its internal structure as well as external parameters such as temperature, complexing agents, capping agents and $\mathrm{pH}$ of the solution [26]. Regarding the formation of $\mathrm{ZnO}$ hollow structures, micro-bubbles of $\mathrm{NH}_{3}$ gas produced in the reaction system with the participation of $\mathrm{NH}_{4} \mathrm{OH}$ must have played a crucial role, since no other templates, surfactants or emulsion were used. $\mathrm{NH}_{4} \mathrm{OH}$ can be easily dissolved in ethylene glycol to give a basic environment (Eq. (3)), while $\mathrm{NH}_{3}$ can also be removed from water-ethylene glycol solution on boiling due 

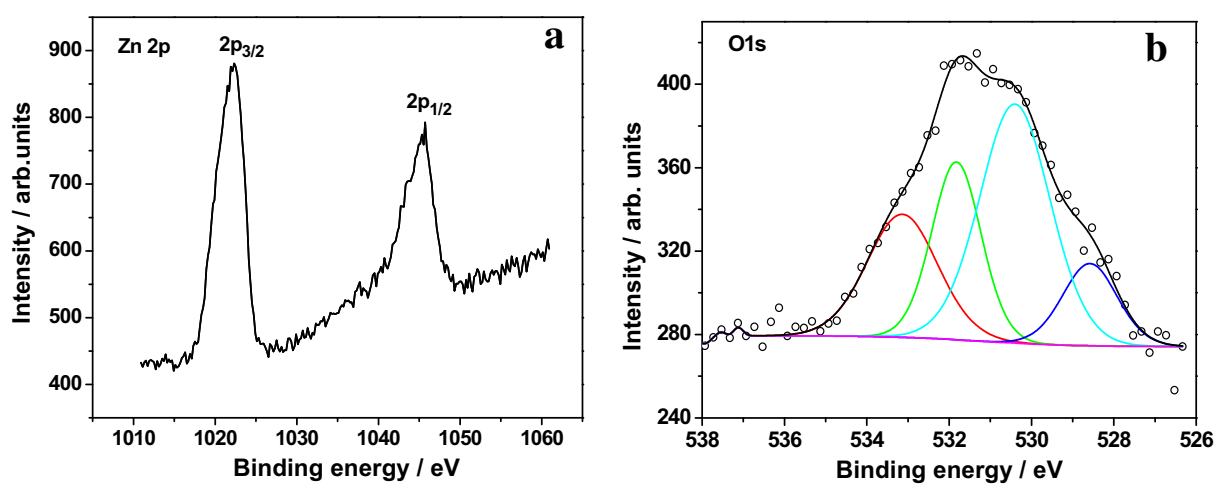

Fig. 2. XPS spectra of (a) Zn (2p) and (b) O (1s).

to the difference in boiling point. Hence, there exists equilibrium (Eq. (4)) when $\mathrm{NH}_{4} \mathrm{OH}$ is maintained at $160{ }^{\circ} \mathrm{C}$ in an airtight autoclave [15].

$$
\begin{aligned}
& \mathrm{NH}_{4} \mathrm{OH} \rightleftharpoons \mathrm{NH}_{4}{ }^{+}+\mathrm{OH}^{-} \\
& \mathrm{NH}_{4} \mathrm{OH} \rightleftharpoons \mathrm{NH}_{3(\mathrm{~g})}+\mathrm{H}_{2} \mathrm{O}_{(\mathrm{l})}
\end{aligned}
$$

The presence of ethylene glycol has a significant influence on the morphology of the $\mathrm{ZnO}$ product. Here, ethylene glycol serves two purposes: advocating the formation of $\mathrm{ZnO}$ crystals and adsorbing on the polar surface of $\mathrm{ZnO}$ [27]. At a low concentration of ammonia $(0.5 \mathrm{ml})$, the two hydroxyl groups of ethylene glycol could effectively attach to the $\left(\begin{array}{llll}0 & 0 & 0 & 1\end{array}\right)$ surface of $\mathrm{ZnO}$ crystals due to the slightly positive charged $\mathrm{Zn}$ surface. This interaction could inhibit crystal growth along ( $\left.\begin{array}{llll}0 & 0 & 0 & 1\end{array}\right)$ direction and lead to the formation of $\mathrm{ZnO}$ nanoparticles (Fig. 3a). The nanoparticles aggregated into spheres to minimize the interfacial energy $[28,29]$ resulting in the formation of densely packed spherical structures of diameter 4-5 $\mu \mathrm{m}$. As the concentration of ammonia increases to $1 \mathrm{ml}$, one can clearly observe the existence of a hole. The $\mathrm{ZnO}$ nuclei aggregate together around the gas-liquid interface, and finally hollow nanorod-based spheres formed [15]. The size of the hole is found to be in the range of $0.8-1.2 \mu \mathrm{m}$. The $\mathrm{ZnO}$ nanorods (200-350 nm) are assembled around the hole (Fig. 3b). During this process, new nuclei can be continually produced and adhere to $\left(\begin{array}{llll}0 & 0 & 0 & 1\end{array}\right)$ surface of $\mathrm{ZnO}$ particles because of limited diffusion in the presence of ammonia [30]. This favors secondary growth along

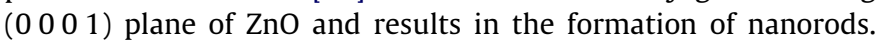
On further increase in ammonia concentration to $1.5 \mathrm{ml}$, one can observe the large number of hollow spheres made of well-arranged nanorods (Fig. 3c-e). These hollow spheres resemble pot morphology (Fig. 3d). The ZnO hollow structures have many advantages over the previous reports in terms of product quality (better morphology control, good monodispersity and high yield) and reaction conditions (lower temperatures and pressures), and formation mechanism [31-34]. Hollow spheres disappear and free nanorods appear when the quantity of ammonia is increased to $2 \mathrm{ml}$ (Fig. 3f).

Fig. 4 shows the TEM images and corresponding selected-area electron diffraction (SAED) pattern of $\mathrm{ZnO}$ spheres prepared at $160{ }^{\circ} \mathrm{C}$ for $1 \mathrm{~d}$ using $0.5 \mathrm{ml}$ ammonia solution. The $\mathrm{ZnO}$ spheres were made up of nanoparticles with a diameter of 20-30 nm which can be clearly observed in Fig. 4a and b. All of these nanoparticles are single crystalline in nature and can be indexed as the hexagonal $\mathrm{ZnO}$ phase as evidenced from the SAED pattern (Fig. 4c). This result is consistent with the XRD results.

\subsection{Raman spectroscopy}

Raman spectroscopy was carried out to study the vibrational properties of the $\mathrm{ZnO}$ crystals. Fig. 5 represents the Raman spectrum of the samples in the range of $80-1000 \mathrm{~cm}^{-1}$. Wurtzite $\mathrm{ZnO}$ belongs to the $C_{6 \mathrm{~V}}(P 63 \mathrm{mc})$ space group [35]. According to group theory, $\Gamma_{\text {opt }}=A_{1}+2 B_{1}+E_{1}+2 E_{2}$ vibrational modes are possible $[36,37]$. Among these vibrational modes, $A_{1}, E_{1}$, and $E_{2}$ are Raman active and $B_{1}$ is Raman forbidden. In addition, $A_{1}$ and $E_{1}$ are infra-red active and can split into longitudinal and transverse optical components. The sharp band at $432 \mathrm{~cm}^{-1}$ is attributed to the $\mathrm{ZnO}$ nonpolar optical phonons high $E_{2}$ vibration mode, which corresponds to the characteristic band of the wurtzite phase. The band at $383 \mathrm{~cm}^{-1}$ corresponds to $A_{1}$ symmetry with the TO model. The bands at 208 and $333 \mathrm{~cm}^{-1}$ observed in the spectrum are due to the second modes. In addition, a sharp and intensive band centered at $98 \mathrm{~cm}^{-1}$, can be assigned to the $E_{2}$ low vibration mode [37]. The vibration mode at $570 \mathrm{~cm}^{-1}$ is LO modes with $E_{1}$ symmetry of $\mathrm{ZnO}$. It is believed that the appearance of the $E_{1}(\mathrm{LO})$ mode generally results from impurities and structural defects [38], which is in accordance with the results obtained from EDS.

\subsection{Energy-dispersive spectroscopy}

The chemical purity of $\mathrm{ZnO}$ as well as its stoichiometry was investigated by EDS analysis. The EDS spectrum (Fig. 6) clearly indicates that the hollow spheres are composed of only $\mathrm{Zn}$, and $\mathrm{O}$, in addition to the $\mathrm{Cu}$ signal arising from the copper TEM grid. Elemental analysis reveals that the atomic ratio of $\mathrm{Zn:O}$ is 55.3:44.7, indicating the presence of oxygen deficiency, which might have been caused during the rapid formation of $\mathrm{ZnO}$ under solvothermal conditions. These crystal defects are important parameters for the materials to exhibit a good catalytic activity.

\subsection{Catalytic property}

Friedel-Crafts alkylation and acylation of aromatic hydrocarbons have been studied extensively using Lewis acid catalysts, such as, $\mathrm{BF}_{3}, \mathrm{AlCl}_{3}, \mathrm{FeCl}_{3}, \mathrm{TiCl}_{4}$ and protonic acid such as $\mathrm{HF}$, $\mathrm{H}_{2} \mathrm{SO}_{4}$ [39]. But, the use of conventional Lewis and mineral acid catalysts has led to environmental problems, especially in largescale production sites. Hence, there is a need to find newer catalyst systems to replace conventional acids for the Friedel-Crafts reactions. Several solid materials such as alumina, silica gels and clays have commonly been used in surface organic chemistry for the preparation of various useful organic compounds [40].

Nanomaterials are expected to have significant differences from their bulk counterparts in both chemical reactivity and physical properties. In order to understand the catalytic properties of the $\mathrm{ZnO}$ materials, Friedel-Crafts acylation of anisole and benzoyl chloride (Fig. 7) was carried out and the results are summarized in Table 1 . The conversion of the $\mathrm{ZnO}$ hollow spheres is $\sim 98 \%$ in 20 min as compared to the commercial $\mathrm{ZnO}(\sim 41 \%)$ and the results are reported by Du et al. [41]. It is also interesting to note that the conversion rate of regenerated $\mathrm{ZnO}$ hollow sphere is $~ 95 \%$. The 

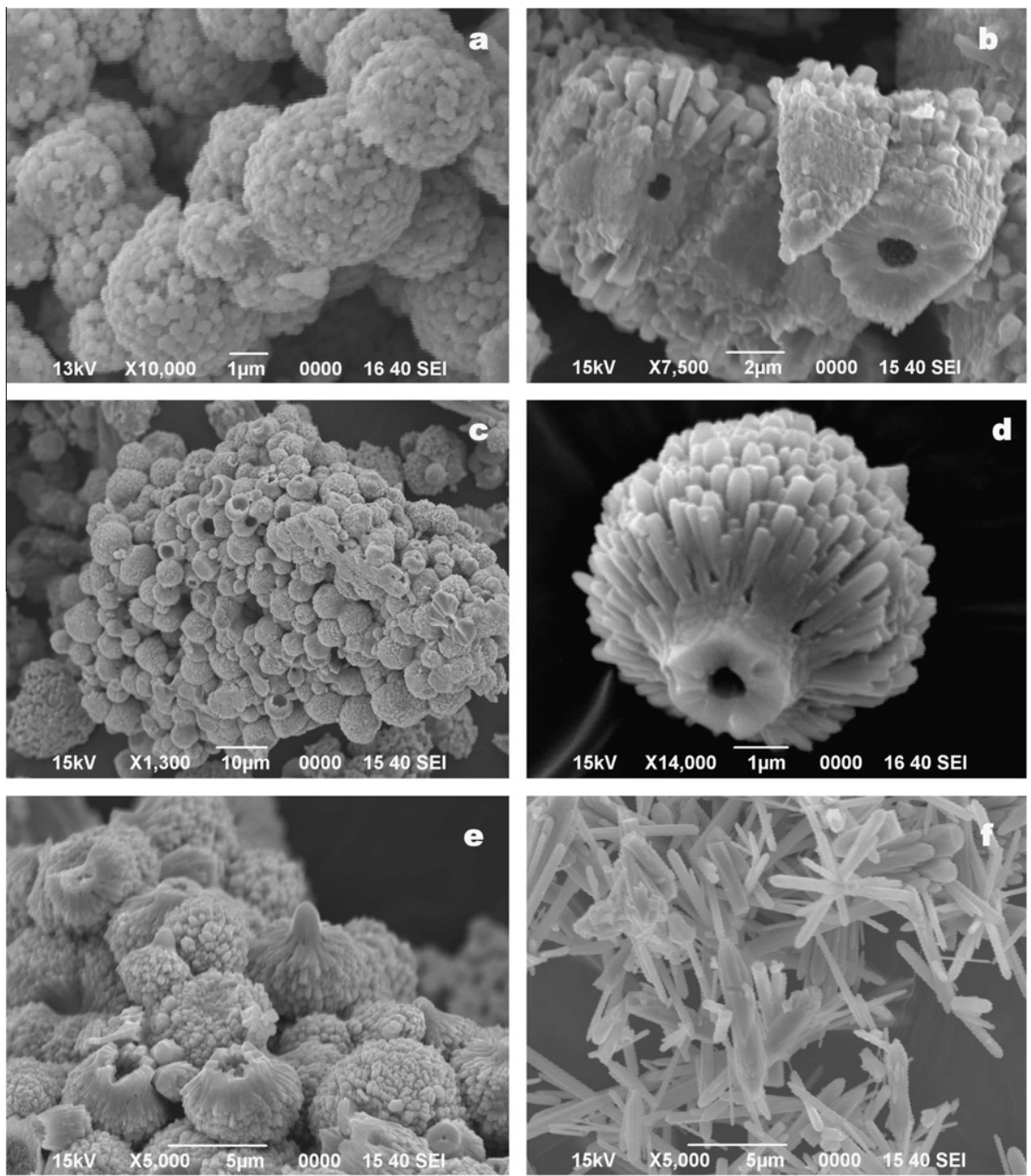

Fig. 3. SEM images of the $\mathrm{ZnO}$ products prepared using (a) 0.5 , (b) 1 , (c-e) 1.5 and (f) $2 \mathrm{ml}$.
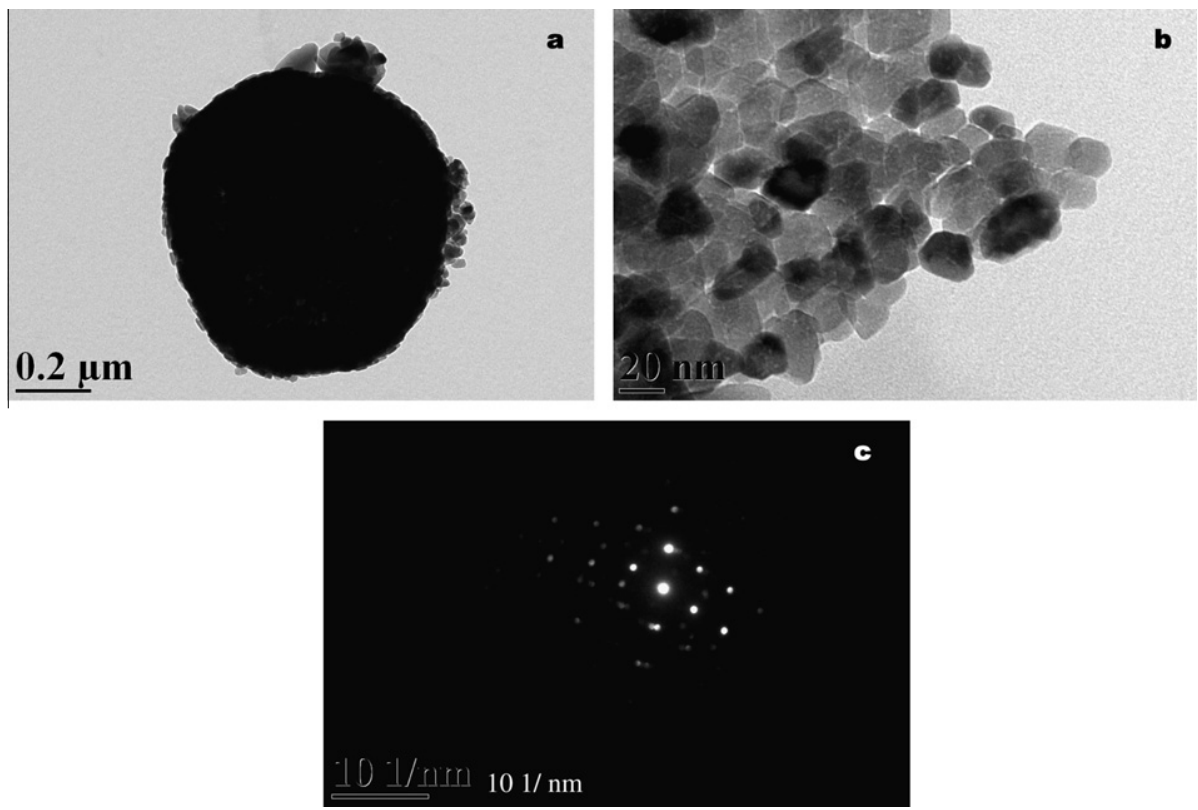

Fig. 4. ( $a$ and b) TEM images of the hollow structured $\mathrm{ZnO}$ and (c) SAED pattern of the ZnO. 


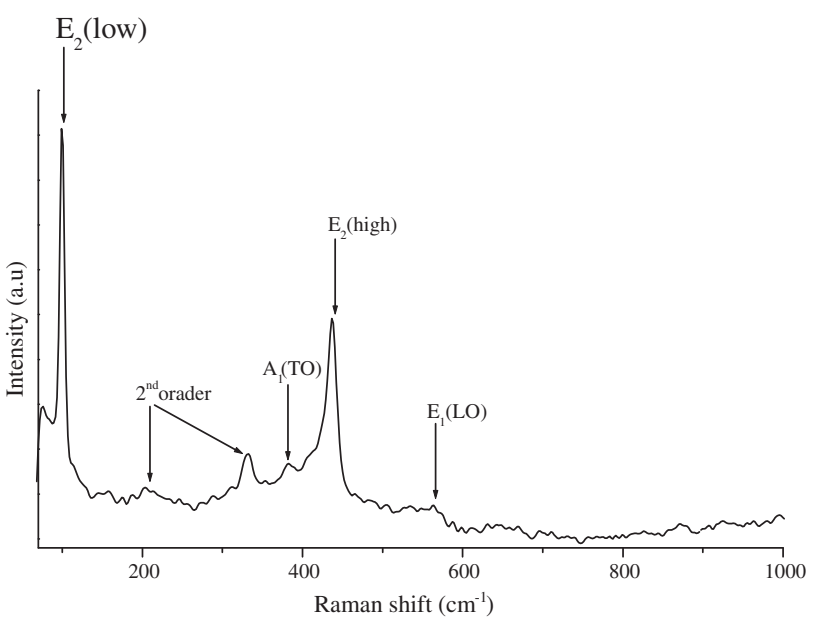

Fig. 5. Raman spectrum of hollow structured $\mathrm{ZnO}$.

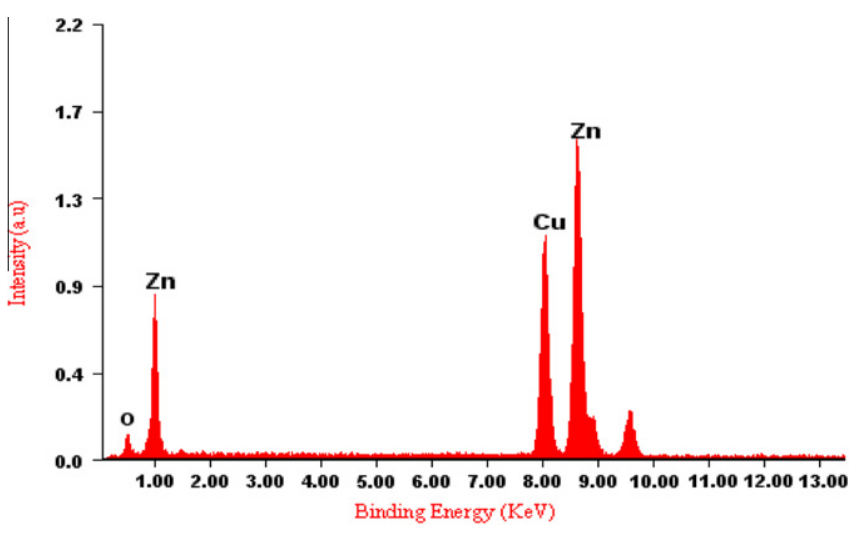

Fig. 6. EDS spectrum of $\mathrm{ZnO}$.

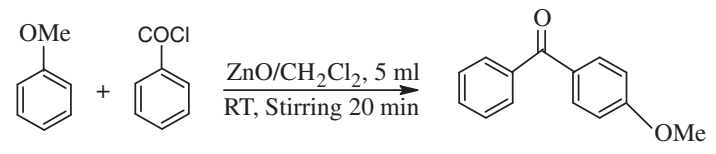

Fig. 7. Friedel-Crafts acylation of anisole with benzoyl chloride in dichloromethane.

\section{Table 1}

Comparison of catalytic efficiency (\% yield) of commercial, solvothermally derived hollow spheres and regenerated $\mathrm{ZnO}$.

\begin{tabular}{lll}
\hline Catalyst & $\begin{array}{l}\text { Reaction time } \\
(\mathrm{min})\end{array}$ & \% of yield \\
\hline- & 20 & 0 \\
Commercial ZnO & 20 & 41 \\
ZnO hollow spheres & 20 & 98 \\
Regenerated ZnO hollow spheres & 20 min & 95 \\
\hline
\end{tabular}

high catalytic activity is due to the existence of a large number of active sites such as Lewis acid and oxygen deficiency in nanocrystalline $\mathrm{ZnO}$ as compared to the commercial $\mathrm{ZnO}$ powder [42].

\section{Conclusion}

Hollow structured $\mathrm{ZnO}$ with building units of nanoparticles and nanorods can be constructed via a solvothermal method without using any templates. In this method, ethylene glycol serves only as a capping agent but ammonia acts as both complexing and capping agent. The preliminary measurement of the catalytic properties suggests that the obtained $\mathrm{ZnO}$ materials could have potentially valuable applications in Friedel-Crafts acylation for the synthesis of industrially important and useful organic compounds.

\section{Acknowledgements}

The authors acknowledge the financial support from the Department of Science and Technology, NSTI Phase-IV, New Delhi, Government of India. We also thank Prof. Sarala Upadhya, Department of Mechanical Engineering, UVCE, Bangalore, for recording the SEM images.

\section{References}

[1] M.F. Garca, A.M. Arias, J.C. Hanson, J.A. Rodriguez, Chem. Rev. 104 (2004) 4063.

[2] W. Chen, Y.H. Lu, M. Wang, L. Croner, H. Paul, H.J. Fecht, J. Bednarcik, K. Stahl, Z.L. Zhang, U. Wiedwald, U. Kaiser, P. Ziemann, T. Kikegawa, C.D. Wu, J.Z. Jiang, J. Physc. Chem. C 113 (2009) 1320.

[3] W. Peng, S. Qu, G. Cong, Z. Wang, Cryst. Growth Des. 6 (2006) 1518.

[4] K.L. Chopra, S.R. Das, Thin Film Solar Cells, Plenum, New York, 1983.

[5] K.S. Weissenrieder, J. Muller, Thin Solid Films 300 (1997) 30.

[6] M. Yoshimoto, S. Takagi, Y. Umemura, M. Hada, H. Nakastuji, J. Catalysis 173 (1998) 53.

[7] W. An, X. Wu, X.C. Zeng, J. Phys. Chem. C 112 (2008) 5747.

[8] J.I. Shulin, Y.E. Changhui, J. Mater. Sci. Technol. 24 (2008).

[9] (a) Y.G. Sun, Y.N. Xia, Science 298 (2002) 2176;

(b) Y.L. Wang, L. Cai, Y.N. Xia, Adv. Mater. 17 (2005) 473;

(c) B.T. Holland, C.F. Blanford, A. Stein, Science 281 (1998) 538;

(d) A. Imhof, D.J. Pine, Nature 389 (1997) 948.

[10] H.J. Fan, R. Scholz, F.M. Kolb, M. Zacharias, U. Gosele, Solid State Comm. 130 (2004) 517

[11] Y.H. Leung, H. Tamk, A.B. Djurisic, M.H. Xie, W.K. Chan, D. Lu, W.K. Ge, J. Cryst. Growth 283 (2005) 134.

[12] Z.Y. Jiang, Z.X. Xie, X.H. Zhang, S.C. Lin, T. Xu, S.Y. Xie, R.B. Huang, L.S. Zheng Adv. Mater. 16 (2004) 904.

[13] S. Ravindran, G.T.S. Andavan, C. Ozkan, Nanotechnology 17 (2006) 723.

[14] J. Duan, X. Huang, E. Wang, H. Ai, Nanotechnology 17 (2006) 1786.

[15] Z. Li, Y. Xie, Y. Xiong, R. Zhang, New J. Chem. 27 (2003) 1518.

[16] C. Yan, D. Xue, J. Phys. Chem. B 110 (2006) 7102.

[17] C. Yan, D. Xue, J. Phys. Chem. B 110 (2006) 11076.

[18] M.C. Neves, T. Trinidade, A.M.B. Timmons, D.J. Pedrosa, Mater. Res. Bull. 36 (2001) 1099.

[19] P. Lipowsky, M. Hirscher, R.C. Hoffmann, J. Bill, F. Aldinger, Nanotechnology 18 (2007) 165603.

[20] L. Shi, F. Du, Mater. Res. Bull. 42 (2007) 1550.

[21] J.S. Lee, S.C. Choi, J. Eur. Ceramic Soc. 25 (2005) 3307.

[22] Corrie, L. Carnes, K.J. Klabunde, Langmuir 16 (2000) 3764.

[23] J.F. Moulder, W.F. Stickle, P.E. Sobol, K.D. Bomben, in: J. Chastain (Ed.), Hand Book of X-ray Photoelectron Spectroscopy, Perking-Elmer Corporation, Minnesota, USA, 1992.

[24] Z. Jia, Y. Tang, L. Luo, B. Li, Cryst. Growth Des. 8 (2008) 2116.

[25] K.X. Yao, R. Sinclair, H.C. Zeng, J. Phys. Chem. C 111 (2007) 2032.

[26] Q. Wu, X. Chen, P. Zhang, Y. Han, X. Chen, Y. Yan, S. Li, Cryst. Growth Des. 8 (2008) 3010.

[27] S.K.N. Ayudhya, P. Tonto, O. Mekasuwandumrong, V. Pavarajarn, P. Praserthdam, Cryst. Growth Des. 6 (2006) 2446.

[28] J. Joo, S.G. Kwon, J.H. Yu, T. Hyeon, Adv. Mater. 17 (2005) 1873

[29] C. Wu, Y. Xie, L. Lei, S. Hu, C.Q. Yong, Adv. Mater. 18 (2006) 1727.

[30] M. Tsuji, M. Hashimoto, Y. Nishizawa, M. Kubakawa, T. Tsuji, Chem. Eur. J. 11 (2005) 440.

[31] Y.F. Zhu, D.H. Fan, W.Z. Shen, J. Phys. Chem. C 111 (2007) 18629.

[32] Z. Chen, L. Gao, Cryst. Growth Des. 8 (2008) 460.

[33] J. Zhang, L. Sun, J. Yin, H. Su, C. Liao, C. Yan, Chem. Mater. 14 (2002) 4172.

[34] S. Ashoka, G. Nagaraju, C.N. Tharamani, G.T. Chandrappa, Mater. Lett. 63 (2009) 873.

[35] M. Kadota, Jpn. J. Appl. Phys. Part 136 (1997) 3076.

[36] T.C. Damen, S.P.S. Porto, B. Tell, Phys. Rev. 142 (1966) 570.

[37] A. Kaschner, U. Haboeck, M. Strassbureg, G. Kaczmarczky, A. Hoffmann, C. Thomsen, A. Zeuner, H.R. Alves, D.M. Hoffmann, B.K. Meyer, Appl. Phys. Lett. 80 (2002) 1909.

[38] C. Bundesmann, N. Ashkenov, M. Schubert, D. Spemann, T. Butz, E.M. Kaidashev, et al., Appl. Phys. Lett. 82 (2003) 2260.

[39] (a) A. Olah, Friedel-Crafts and Related Reactions, vols. 1-4, Wiley-Interscience, New York, London, 1963-1964.;

(b) G.A. Olah, G.K.S. Prakash, J. Sommer, Superacids, Wiley-Interscience, Brisbane, Toronto, 1985. 
[40] (a) G.H. Posner, Angew. Chem., Int. Ed. Engl. 17 (1978) 487;

(b) A. Mckillop, D.W. Young, Synthesis 401 (1979) 408;

(c) H. Firouzabadi, N. Iranpoor, S. Sobhani, Tetrahedron Lett. 43 (2002) 477;

(d) H. Firouzabadi, N. Iranpoor, S. Sobhani, A. Sardarian, Tetrahedron Lett. 42 (2001) 4369;

(e) H. Sharghi, K. Niknam, A.R. Massah, J. Heterocycl. Chem. 36 (1999) 601;

(f) A. Shockravi, H. Sharghi, H. Valizadeh, M.M. Heravi, Phosphorus Sulfur
Silicon 177 (2002) 2555;

(g) F. Kazemi, H. Sharghi, M.A. Nasseri, Synthesis 2 (2004) 205.

[41] J. Du, Z. Liu, Y. Huang, Y. Gao, B. Han, W. Li, G. Yang, J. Cryst. Growth 280 (2005) 126.

[42] R. Richards, W. Li, S. Decker, C. Davidson, O. Koper, V. Zaikovski, A. Volodin, T. Rieker, K.J. Klabunde, J. Am. Chem. Soc. 122 (2000) 4921. 